\title{
Selective Regulation of Cellular Cyclooxygenase by Dexamethasone and Endotoxin in Mice
}

\author{
Jaime L. Masferrer," Ben S. Zweifel, ${ }^{\star}$ Karen Seibert, ${ }^{*}$ and Philip Needleman*; \\ *Department of Pharmacology, Washington University School of Medicine, St. Louis, Missouri 63110; \\ and ${ }^{\ddagger}$ Monsanto Company, St. Louis, Missouri 63198
}

\begin{abstract}
We have studied the effect of glucocorticoids administered in vivo on the activity and synthesis of the cyclooxygenase enzyme (COX) in mice treated with or without concurrent intravenous administration of LPS. Mouse peritoneal macrophages from LPS-treated animals showed a two to three fold increase in COX activity determined by the production of $\mathrm{PGE}_{2}$ and $\mathrm{PGI}_{2}$ after stimulation of the cells with exogenous arachidonate. Dexamethasone injected simultaneously with LPS, 12 h before killing of the animal and removal of the macrophages, completely blocked the LPS-induced increase COX activity in peritoneal macrophages. The regulation observed in $\mathrm{COX}$ activity by LPS and dexamethasone are due primarily to changes in COX mass as determined by immunoprecipitation of ${ }^{35}$ S]methionine endogenously labeled enzyme. In contrast, the COX present in the nonadherent cells and in renal medullary microsomes obtained from the same animals, showed no significant changes between treatments. These results indicate that LPS in vivo stimulates COX synthesis in the peritoneal macrophages but not in the kidney. The effect of dexamethasone to inhibit COX synthesis is selective to the LPS-induced enzyme. (J. Clin. Invest. 1990. 86:1375-1379.) Key words: glucocorticoid • prostaglandin $\bullet$ macrophage $\bullet$ LPS $\bullet$ leukotrienes
\end{abstract}

\section{Introduction}

Anti-inflammatory steroids together with nonsteroidal anti-inflammatory drugs are widely employed for the treatment of acute and chronic inflammatory diseases. While the mechanism of action of nonsteroidal agents has been shown to result from blockade of prostanoid production by inhibition of cyclooxygenase $(\mathrm{COX})^{1}(1)$, the mechanism(s) of anti-inflammatory steroids is still unknown. Glucocorticoids modulate the

Address reprint requests to Dr. Jaime L. Masferrer, Department of Pharmacology, Box 8103, Washington University School of Medicine, 660 South Euclid Avenue, St. Louis, MO 63110. 1990.

Received for publication 30 May 1990 and in revised form 18 July

1. Abbreviations used in this paper: COX, cyclooxygenase; DEX, dexamethasone.

J. Clin. Invest.

(c) The American Society for Clinical Investigation, Inc.

$0021-9738 / 90 / 10 / 1375 / 05 \$ 2.00$

Volume 86, October 1990, 1375-1379 synthesis of a number of proteins, among these a $35-40 \mathrm{kD}$ polypeptide (lipocortin) which was thought to inhibit phospholipase $A_{2}(2)$, thereby reducing the formation of proinflammatory eicosanoid products. Also, human recombinant lipocortin 1 has been shown to have anti-inflammatory properties in the rat paw edema test (3). However, recent studies have raised serious doubts about glucocorticoid-induced lipocortin formation (4), and whether lipocortin inhibits phospholipase (5) or rather acts as a phospholipid binding protein (6). Moore and Holt (7), and Wood and co-workers (8) have reported data that suggest that glucocorticoids inhibit COX activity. Also, it has been shown that dexamethasone (DEX) suppress cyclooxygenase messenger RNA levels in cultured vascular cells (9). We have recently demonstrated that DEX inhibits in vitro COX activity by suppressing the de novo synthesis of COX enzyme in human dermal fibroblasts (10), cultured monocytes (10a), and macrophages (unpublished results). However, this effect of DEX must be validated in vivo in order to fully unravel the potential therapeutic value of this observation and to avoid interpretation of mechanism fully dependent on tissue culture conditions. Although several in vivo studies showed that eicosanoid metabolism is not affected by steroid administration (12-18), we report the effect of glucocorticoids administered in vivo on the activity of COX and 5-lipoxygenase enzymes in normal condition and in a systemic model of inflammation, e.g., endotoxin LPS administered in vivo.

\section{Methods}

Preparation of animals. Male Balb C mice (8-9 wk old) were used and divided into four treatment groups. Group 1 received saline, group 2 received endotoxin, group 3 received endotoxin with dexamethasone, and group 4 received dexamethasone only. Endotoxin (LPS from $\mathrm{Sal}$ monella typhimurium $\operatorname{Re} C 30 / C 21$; Ribi ImmunoChem Research, Inc., Hamilton, MT) was given as a single intravenous injection (tail vein) of $50 \mu \mathrm{g}$ in $200 \mu \mathrm{l}$ of sterile saline or in combination with dexamethasone $(5 \mathrm{mg} / \mathrm{kg})$. After treatment, all mice were returned to their cages with free access to food and water until they were used. At specified times after treatment, mice were sacrificed in a $\mathrm{CO}_{2}$ chamber and the peritoneal cells were obtained by lavaging the peritoneal cavity with cold PBS. Cell counts were performed using a hemocytometer and differentials performed on cell preparations made with a cytospin (Shandon Southern Instruments Inc., Pittsburgh, PA) stained with Giemsa.

Macrophage isolation. Peritoneal cells (1-2 $\times 10^{6}$ cells) were allowed to adhere to 24-well tissue culture plates for $2 \mathrm{~h}\left(37^{\circ} \mathrm{C}, 5 \% \mathrm{CO}_{2}\right)$ in DMEM, $10 \%$ fetal calf serum, and $100 \mu \mathrm{g}$ penicillin/streptomycin. The nonadherent cells were removed by washing three times in calcium and magnesium-free PBS. The cell preparation was more than 97\% viable, as assayed by trypan blue exclusion, and consisted of 
greater than $90 \%$ macrophages as judged by morphological criteria under the light microscope.

COX activity. Cellular COX activity in the macrophages was measured by incubating the intact cells in DMEM with $30 \mu \mathrm{M}$ arachidonic acid for $10 \mathrm{~min}$. Aliquots of the incubation mixture were assayed for $\mathrm{PGE}_{2}, 6-\mathrm{keto}-\mathrm{PGF}_{1 \alpha}$, and $\mathrm{TxB}_{2}$ formation by specific radioimmunoassays $(19,20)$. The cells were washed with PBS and solubilized in $0.62 \mathrm{~N}$ $\mathrm{NaOH}$ for protein determination by the Coomassie brilliant blue reagent (21).

Metabolic labeling with $\left[{ }^{35}\right.$ S $]$ methionine and immunoprecipitation of COX. Macrophages $\left(20 \times 10^{6}\right.$ cells) obtained from the four different treatment groups were incubated for $30 \mathrm{~min}$ in Met-free DMEM, washed with the same media, and incubated in the presence of $\left[{ }^{35}\right.$ S]methionine $(0.5 \mathrm{mCi}[10 \mathrm{mCi} / \mathrm{ml}$; Amersham Corp., Arlington Heights, IL] per well) for $4 \mathrm{~h}$. Cells were washed, collected, and solubilized in solubilization buffer: Tris- $\mathrm{HCl} 50 \mathrm{mM}$; EDTA $10 \mathrm{nM}$; NP40 $1 \%$, diethyldithiocarbamic acid (DCC) $1 \mathrm{mM} ; \mathrm{pH}=8.0$. After sonication and centrifugation $(100,000 \mathrm{~g}, 15 \mathrm{~min})$, aliquots of the supernatant containing the solubilized COX were immunoprecipitated with specific COX antibody (10) after preclearance with normal rabbit serum. Immunoprecipitation was completed by using protein-A-Sepharose (Sigma Chemical Co., St. Louis, MO). After three washes with 50 mM Tris- $\mathrm{HCl}, 5 \mathrm{mM}$ EDTA, $150 \mathrm{mM} \mathrm{NaCl}, 0.5 \%$ Triton X-100, $0.1 \%$ $\mathrm{SDS}, 10 \mathrm{U} / \mathrm{ml}$ Trasylol, $\mathrm{pH}=8.0$, two further washes with the same buffer without detergents were made and the pellets processed for SDS/PAGE as described (10). The proteins in the gel were fixed, soaked in Amplify (Amersham Corp.), dried, and exposed to XAR-5 film (Kodak Laboratory and Specialty Chemicals, Rochester, NY) at $-70^{\circ} \mathrm{C}$. COX band is determined by its migration on SDS/PAGE $\approx 70 \mathrm{Kd}$ protein and by cold competition experiments with $5 \mu \mathrm{g}$ of purified COX (Cayman Chemical Co., Ann Arbor, MI). Relative intensities of COX band were determined by laser densitometric scanning of the films under conditions in which band intensity was proportional to radioactivity and exposure time.

Kidney microsomal COX. Microsomes were prepared as previously described (22). Briefly, medullary portions from kidneys obtained from the different treatment groups were homogenized in phosphate buffer and the $10,000 \mathrm{~g}$ supernatant was isolated. Microsomes were then obtained from a $100,000 \mathrm{~g}$ spin, and the microsomal pellet resuspended in phosphate buffer. Microsomes were then incubated with 30 $\mu \mathrm{M}$ arachidonic acid in the presence of $1 \mu \mathrm{M}$ epinephrine for $10 \mathrm{~min}$ at $37^{\circ} \mathrm{C}$. The reaction was stopped by cooling the tubes at $0^{\circ} \mathrm{C}$ before testing for the formation of $\mathrm{PGE}_{2}$.

Induction of leukotrienes formation by zymosan. We used a modification of the method of Doherty et al. $(23,11)$ that is known to produce an acute model of inflammation with synthesis of peptidoleukotrienes without cellular influx for at least $2 \mathrm{~h}$. Mice that have been injected intravenously with LPS, DEX, or both for $12 \mathrm{~h}$ received intraperitoneal injections of $1 \mathrm{mg}$ of zymosan in $1 \mathrm{ml}$ of sterile PBS. At 1 or $2 \mathrm{~h}$ after the injections, mice were killed using $\mathrm{CO}_{2}$ and the peritoneum was lavaged with $2 \mathrm{ml}$ of ice-cold saline. The cell content of peritoneal lavage fluids as well as differential analysis was made as previously described. The lavage fluid was centrifuged $10,000 \mathrm{~g}$ for $5 \mathrm{~min}$ and the supernatants were frozen at $-20^{\circ} \mathrm{C}$ until assays.

Some animals were treated with indomethacin, $1 \mathrm{mg} / \mathrm{kg}$ s.c. $30 \mathrm{~min}$ before the zymosan injections. $\mathrm{LTB}_{4}$ and $\mathrm{LTC}_{4}$ were assayed by specific immunoassays already described (24).

Statistics. Statistical analysis was performed by a one-way analysis of variance. If this indicated significance, comparison between groups were analyzed by a Student's $t$ test. Significance was accepted at $P$ $<0.05$.

\section{Results}

Effects of LPS and DEX in vivo. Intravenous injections of LPS ( $50 \mu \mathrm{g}$ per mouse), dexamethasone $(5 \mathrm{mg} / \mathrm{kg}$ ), or both produced no change in the total number of intraperitoneal leukocytes, mainly macrophages, obtained $12 \mathrm{~h}$ after administration (Table I). When COX activity was measured in the isolated
Table I. Intraperitoneal Leukocytes Number after $12 \mathrm{~h}$ of LPS and Dexamethasone

\begin{tabular}{llccc}
\hline & Polymorphs & Macrophages & Lymphocytes & Total cells \\
\hline \multicolumn{4}{c}{ cells/10-5 } \\
Control & $0.95 \pm 0.02$ & $12.1 \pm 3.1$ & $3.2 \pm 0.2$ & $16 \pm 4$ \\
LPS & $0.82 \pm 0.01$ & $10.5 \pm 1.7$ & $2.8 \pm 0.4$ & $14 \pm 2$ \\
LPS + DEX & $0.90 \pm 0.01$ & $11.5 \pm 2.1$ & $3.0 \pm 0.6$ & $15 \pm 3$ \\
DEX & $0.12 \pm 0.01^{*}$ & $14.2 \pm 2.0$ & $3.9 \pm 0.5$ & $18 \pm 3$ \\
\hline
\end{tabular}

Peritoneal cells were collected after $12 \mathrm{~h}$ of treatments, analyzed by counting total cells and differential analysis using Giemsa stain Mean \pm SE; $n=3 . t$ test ${ }^{*} P<0.001$ vs. control.

macrophages, we found that LPS produced a two- to threefold increase in the activity of the COX enzyme when measured as the production of $\mathrm{PGE}_{2}$ or 6-keto-PGF ${ }_{1 \alpha}$ (Fig. $1 A$ and $B$ ). COX activity was slightly diminished in the DEX group ( $P$ $<0.05$ ) when assessed as $\mathrm{PGE}_{2}$ formation (Fig. $1 A$ ). However, when DEX was co-injected with LPS, a complete inhibition of the LPS enhancement of COX activity was observed (Fig. $1 \mathrm{~A}$ and $B$ ), returning back to control levels. Therefore, DEX only inhibited the COX enzyme that was induced by LPS. Thromboxane production by the mice macrophages was found to be a minor component in the fate of arachidonic acid and its production was not modified by the different treatments (Fig. 1 $C)$. The cells that did not attach to the plastic, mainly lymphocytes, produced very small amounts of prostanoids $309 \pm 30 \mathrm{pg} \mathrm{PGE}_{2} / 10^{6}$ cells with undetectable amounts of 6keto-PGF ${ }_{1 \alpha}$ and thromboxane $B_{2}$. These cells showed no regulation in their COX activity upon different treatments (data not shown).

Effects of LPS and DEX on COX de novo synthesis. To determine if the changes observed in COX activity by the in vivo injections of LPS and DEX were due to regulation in the
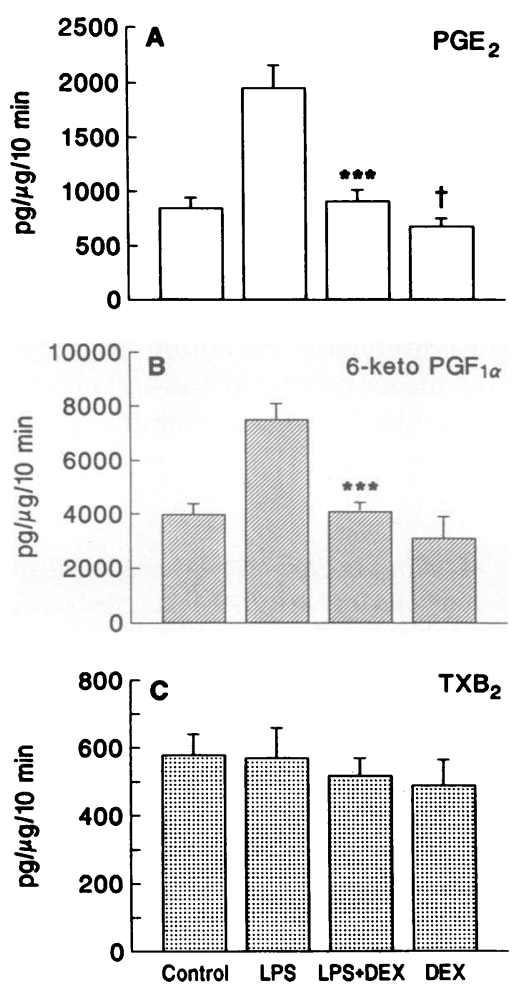

Figure 1. Effect of in vivo LPS and DEX on COX activity in the isolated macrophages. Peritoneal cells were collected after $12 \mathrm{~h}$ of in vivo injections of LPS, DEX, or both. After $2 \mathrm{~h}$ plastic adherence, macrophages COX activity was measured by incubating the cells for 10 min with 30 $\mu \mathbf{M}$ arachidonic acid and prostanoid measured by RIA. Results are the mean $\pm \mathrm{SE} ; n$ $=15 . t$ test $+P<0.05$ vs. control; ${ }^{* * *} P<0.001$ vs. LPS. 
de novo synthesis of the enzyme, we metabolically labeled the COX present in the macrophages obtained from the control and treated animals for $4 \mathrm{~h}$ with $\left[{ }^{35} S\right]$ methionine, and after solubilization, the enzyme was subjected to immunoprecipitation with a specific polyclonal antibody. The total amount of radioactivity associated with cellular protein content did not differ among groups. Laser densitometry analysis of the $\left[{ }^{35}\right.$ S]COX band (Fig. 2) showed that LPS given in vivo produced a threefold increase in the de novo synthesis of COX compared with control cells. Dexamethasone given in vivo resulted in a $40 \%$ reduction in the radioactivity associated with COX, but its major effect was a $80 \%$ inhibition of the LPS-induced COX (Fig. 2). The inhibitory effect of DEX on LPS-induced COX synthesis was dose dependent (Fig. 3), being maximum at a single dose of $5 \mathrm{mg} / \mathrm{kg}$ with an apparent $\mathrm{IC}_{50}$ of 0.5 $\mathrm{mg} / \mathrm{kg}$.

Previous studies $(25,26)$ indicated that in vivo treatment with DEX produced both increases or decreases in the renal COX activity. Using our experimental protocol, we found that $12 \mathrm{~h}$ after injections neither LPS nor DEX produced significant changes in renomedullary microsomal COX activity (control $=1.07 \pm 0.2 ;$ LPS $=0.83 \pm 0.1 ;$ LPS + DEX $=0.78 \pm 0.1 ; \mathrm{DEX}=0.9 \pm 0.1 \mathrm{nmol} / \mathrm{mg}$ protein per $\mathrm{min}$ ).

Effect of LPS and DEX on 5-lipoxygenase activity. After the in vivo injections of LPS, DEX, or both, mice were subjected to an acute inflammatory stimulus by the injection of 1 $\mathrm{mg} / \mathrm{ml}$ zymosan i.p. During the first $2 \mathrm{~h}$ postzymosan administration, there was substantial endogenous metabolism of arachidonic acid in the peritoneum via both the 5-lipoxygenase and the cyclooxygenase pathways $(10,11)$, without marked changes in number or types of intraperitoneal leukocytes. Analysis of the peritoneal lavage fluids (Table II) showed that the major component, 6-keto-PGF ${ }_{1 \alpha}$, was stimulated by LPS and blocked by DEX similar to the changes observed in the macrophages that were analyzed for COX activity in vitro. Leukotriene $\mathbf{B}_{\mathbf{4}}$ was detected in all the peritoneal fluid tested; however, the animals which were injected with LPS or the combination of LPS and DEX showed a $50 \%$ reduction in the $\mathrm{LTB}_{4}$ production after $1 \mathrm{~h}$ of zymosan injections compared with the controls or the animals that received DEX alone. $\mathrm{LTC}_{4}$ production was unchanged after $1 \mathrm{~h}$, but its production was also modestly decreased in the LPS or LPS + DEX group

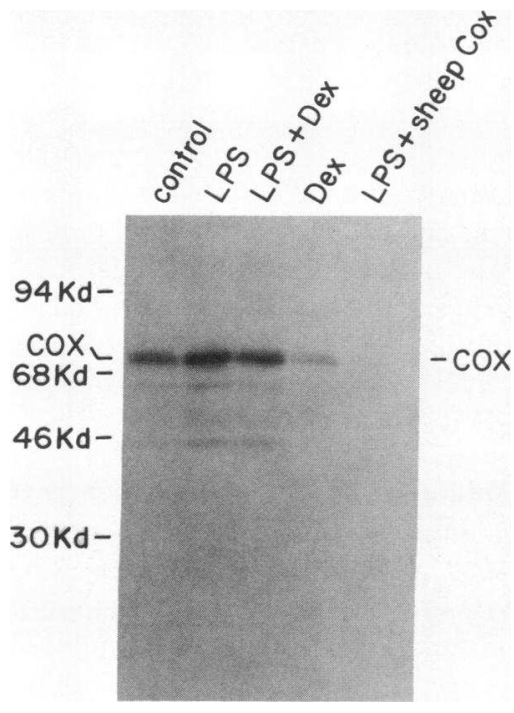

Figure 2. Immunoprecipitation of $\mathrm{COX}$ enzyme levels in macrophages obtained from animals treated with in vivo injections of LPS, DEX, or both. Isolated macrophages were incubated for $4 \mathrm{~h}$ with $\left[{ }^{35} \mathrm{~S}\right]$ methionine and then processed for immunoprecipitation and SDS/PAGE as described. Gels were exposed to $x$-ray film for $2 \mathrm{~h}$ at $-70^{\circ} \mathrm{C}$.

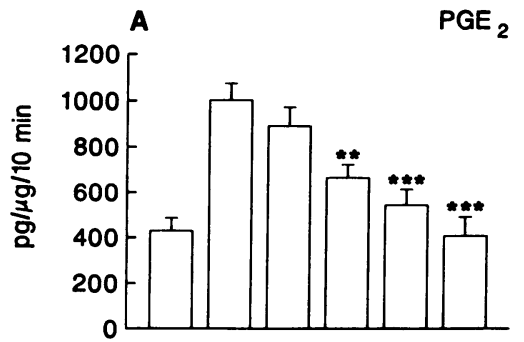

Figure 3. Dose-dependent inhibition by DEX of LPS-induced COX enzyme. Mice were injected with $50 \mu \mathrm{g} \mathrm{LPS}$ simultaneously with and without different amounts of DEX (0.05$50 \mathrm{mg} / \mathrm{kg}$ ) for $12 \mathrm{~h}$. Resident macrophages were cultured and stimulated with $30 \mu \mathrm{M}$ arachidonic acid for 10 min. The media was analyzed by radioimmunoassay for $\mathrm{PGE}_{2}$ $(A)$ and 6-keto-PGF $F_{1 \alpha}$ $(B)$. The data represent the mean \pm SE of two separate experiments, each with three animals per group. $t$ test ${ }^{* *} P$ $<0.01 ;{ }^{* * *} P<0.001$ vs. LPS alone.

at $2 \mathrm{~h}$. Pretreatment of the animals with indomethacin 1 $\mathrm{mg} / \mathrm{kg}$ s.c. $30 \mathrm{~min}$ before zymosan, a dose that inhibited prostaglandin formation by $90 \%$, completely abolished the inhibitory effect of LPS on leukotriene formation, indicating that the reduction in $\mathrm{LTB}_{4}$ and $\mathrm{LTC}_{4}$ observed in the LPS group was probably a sequestration of the free arachidonic acid by the increased COX synthesis resulting in an increased production of prostanoids, especially 6-keto $\mathrm{PGF}_{1 \alpha}$.

\section{Discussion}

The current study was designed to determine the effects of in vivo steroid treatment on the regulation of COX and 5-lipoxygenase enzymes present in resident peritoneal macrophages and in macrophages that have been exposed to the effects of LPS, i.e., a model of shock induced by endotoxin. In this model, high doses of corticosteroids are used to ameliorate the symptoms and survival in human and experimental animals $(16,32)$. We found that LPS selectively induced the de novo synthesis of COX in macrophages resulting in an increased output of 6-keto-PGF ${ }_{1 \alpha}$ in the peritoneal cavity. DEX added in vivo did not alter COX activity present in the nonadherent cells (lymphocytes and PMNs) or renal cells, similar to the results of Erman and Nasjletti (25) in the rat. However, in the peritoneal macrophages we observed a marginal inhibitory effect on basal activity in contrast to a dramatic, dose-dependent ability of DEX to suppress the stimulated synthesis of the LPS-induced enzyme. These results in vivo are in agreement with our previous in vitro data that demonstrate a marked stimulation of the de novo synthesis of COX by either the cytokine IL-1 in human dermal fibroblasts (10) or by LPS in the human blood monocyte (10a), effects that in both instances are completely blocked by DEX (10).

We also investigated the effect on 5-lipoxygenase by DEX in the peritoneal macrophage in vivo. Intraperitoneal zymosan injections produced a rapid activation of the 5-lipoxygenase enzyme as observed by the production of $\mathrm{LTB}_{4}$ and $\mathrm{LTC}_{4}$. DEX treated animals demonstrated no changes in their ability to produce leukotrienes, indicating that upon activation, 5-li- 
Table II. Eicosanoid Formation in Acute Inflammation (Comparison between Mice Exposed to Endotoxin and Dexamethasone)

\begin{tabular}{|c|c|c|c|c|c|c|c|c|}
\hline \multirow[b]{3}{*}{ Treatment } & \multicolumn{4}{|c|}{ Cyclooxygenase products (ng/lavage) } & \multicolumn{4}{|c|}{ 5-lipoxygenase products (ng/lavage) } \\
\hline & \multirow[b]{2}{*}{$\begin{array}{l}\text { Time after } \\
\text { zymosan }\end{array}$} & \multirow[b]{2}{*}{$\mathrm{PGE}_{2}$} & \multirow[b]{2}{*}{$\begin{array}{l}6 \text { keto } \\
\text { PGF }_{1 \alpha}\end{array}$} & \multirow[b]{2}{*}{$\mathrm{TXB}_{2}$} & \multicolumn{2}{|c|}{$\mathrm{LTB}_{4}$} & \multicolumn{2}{|c|}{$\mathrm{LTC}_{4}$} \\
\hline & & & & & - & + INDO & - & + INDO \\
\hline \multirow[t]{2}{*}{ Control } & $1 \mathrm{~h}$ & $0.7 \pm 0.03$ & $7.6 \pm 0.7$ & $0.4 \pm 0.1$ & $3.1 \pm 0.3$ & $4.3 \pm 0.7$ & $6.7 \pm 0.7$ & $8.4 \pm 0.9$ \\
\hline & $2 \mathrm{~h}$ & $0.8 \pm 0.06$ & $5.8 \pm 0.9$ & $0.5 \pm 0.1$ & $4.6 \pm 1.0$ & $7.6 \pm 0.9$ & $3.9 \pm 0.3$ & $5.6 \pm 0.9$ \\
\hline \multirow[t]{2}{*}{ LPS } & $1 \mathrm{~h}$ & $1.7 \pm 0.31^{*}$ & $13.3 \pm 1.8^{*}$ & $0.3 \pm 0.1$ & $1.5 \pm 0.2^{*}$ & $3.6 \pm 0.6$ & $6.4 \pm 1.1$ & $7.9 \pm 1.0$ \\
\hline & $2 \mathrm{~h}$ & $2.5 \pm 0.5^{*}$ & $5.2 \pm 0.4$ & $0.3 \pm 0.1$ & $1.9 \pm 0.2^{*}$ & $7.6 \pm 0.4$ & $1.4 \pm 0.4^{*}$ & $5.3 \pm 0.6$ \\
\hline \multirow[t]{2}{*}{ LPS + DEX } & $1 \mathrm{~h}$ & $0.87 \pm 0.09^{* \dagger}$ & $8.2 \pm 0.7^{\dagger}$ & $0.3 \pm 0.1$ & $1.7 \pm 0.5^{*}$ & $3.9 \pm 1.2$ & $7.6 \pm 1.5$ & $8.6 \pm 0.8$ \\
\hline & $2 \mathrm{~h}$ & $1.3 \pm 0.25^{* \dagger}$ & $5.8 \pm 0.2$ & $0.3 \pm 0.1$ & $2.7 \pm 0.5^{*}$ & $9.4 \pm 0.6$ & $1.3 \pm 0.1^{*}$ & $4.2 \pm 1.2$ \\
\hline \multirow[t]{2}{*}{ DEX } & $1 \mathrm{~h}$ & $0.63 \pm 0.05$ & $7.8 \pm 0.7$ & $0.4 \pm 0.1$ & $3.6 \pm 0.3$ & $4.7 \pm 1.0$ & $7.5 \pm 0.5$ & $7.6 \pm 0.6$ \\
\hline & $2 \mathrm{~h}$ & $1.1 \pm 0.25$ & $4.8 \pm 0.3$ & $0.4 \pm 0.1$ & $4.1 \pm 0.2$ & $10.0 \pm 1.0$ & $2.9 \pm 0.9$ & $5.9 \pm 1.1$ \\
\hline
\end{tabular}

Acute inflammation was induced in control and treated animals by the intraperitoneal injections of zymosan. Lavage fluid was obtained at 1 and $2 \mathrm{~h}$ for the measurements of eicosanoid products. Results are expressed as mean \pm SE. $n=6 . t$ test ${ }^{*} P<0.01$ vs. control; ${ }^{\dagger} P<0.01$ vs. LPS. Indomethacin blocked more than $90 \%$ prostanoid formation when given $1 \mathrm{mg} / \mathrm{kg}$ subcutaneous $30 \mathrm{~min}$ before zymosan.

poxygenase activity was not modified by the in vivo administration of glucocorticoid. However, we examined only the effect of DEX on an unstimulated lipoxygenase. Therefore we cannot exclude the possibility of a DEX inhibitory effect on 5-lipoxygenase expression in the event of a stimulation by a proinflammatory agent different from LPS. The animals treated in vivo with LPS showed somewhat lower production of $\mathrm{LTB}_{4}$ and $\mathrm{LTC}_{4}$ at 1 and $2 \mathrm{~h}$ after zymosan administration, respectively. However, when COX activity was inhibited by administration of indomethacin to the animals, leukotriene formation returned to control values indicating that in the LPS treated group, the increased synthesis of COX predominates and overrides any ability to produce lipoxygenase products. It is possible that the COX regulation observed in peritoneal macrophages following in vivo administration of LPS and DEX exists in other cell types, possibly endothelial cells and monocytes, given the ability of these cell populations to respond in vitro to LPS and DEX like peritoneal macrophages (33). In our experiments we found no changes in the levels of COX activity present in the renomedullary microsomes derived from the same animals that received LPS, DEX, or both. These results suggest that, at least for glucocorticoid, the inhibitory effect on COX synthesis is cell selective and only becomes highly effective when the enzyme is stimulated with agents like LPS.

Interestingly, unstimulated basal COX activity is unaffected by DEX although metabolic labeling with $\left[{ }^{35} \mathrm{~S}\right] \mathrm{methio-}$ nine showed a $40 \pm 12 \%(n=4)$ reduction in de novo COX synthesis during the incubation period. One possible explanation is that DEX exerts some of its effect on PG formation via increased stability of the existing constitutive enzyme with no net change in total cellular COX activity.

Given the observation that DEX may inhibit differentially the basal and LPS stimulated COX, we hypothesize the possibility of functionally distinct COX enzymes. Clearly, those putative enzyme pools may arise as different gene products, possibly through the expression of different COX genes under regulatory control by glucocorticoids. This hypothesis is currently under investigation.

The in vivo glucocorticoid effect on eicosanoid metabolism we report here differs from previous studies that propose the mechanism of glucocorticoid inhibition of arachidonic acid release is due to the inhibition of phospholipase $A_{2}$ activity by the lipocortins (27). However, recent reports dispute this mechanism of inhibition because (a) lipocortins do not inhibt phospholipase $A_{2}$ activity in vitro $(5,6)$; and $(b)$ dexamethasone does not induce lipocortin mRNA or mass $(4,28)$ in systems where glucocorticoids are known to inhibit eicosanoid formation (28).

Our recent data and others in vitro provide an alternative hypothesis for the regulation of the arachidonic acid metabolism that involves the direct induction and inhibition of the COX. IL-1 (29), phorbol myristate acetate (PMA) (10), PDGF (30), and LPS (submitted) have all been shown to induce COX synthesis in vitro with a subsequent increase in arachidonic metabolite release. In 1982, Hawkey (31) reported that prednisolone inhibits COX activity in vitro in human rectal mucosa, and more recently it has been demonstrated that steroids suppress COX mRNA levels and prostanoid synthesis in cultured vascular cells (9). In our laboratory, we also demonstrated that DEX is able to inhibit the synthesis of COX in vitro in human dermal fibroblasts (10), blood monocytes (submitted), and mouse peritoneal macrophages (unpublished). These in vitro observations coupled in our in vivo demonstration of the DEX inhibition of COX synthesis in vivo suggest that one of the anti-inflammatory mechanisms of the glucocorticoids is the inhibition of COX synthesis. Furthermore, these results suggest that low doses of steroids preferentially suppress cytokine or endotoxin induced COX without suppression of a basal or constitutive COX activity. This new mechanism of action of glucocorticoids has two important clinical implications. First these results suggest that the combination of a nonsteroidal inhibitor of COX with corticosteroids is a rational and nonredundant therapeutic strategy in the treatment of inflammatory disorders. Nonsteroidal agents will inhibit COX nonspecifically, whereas steroids will inhibit the induction of this enzyme in the context of the inflammatory response. Thus, these agents have nonoverlapping pharmacologic properties. Additionally, this study suggests that there may be strategies to interrupt COX metabolism without interfering with the important constitutive activities of prostaglandins, such as maintenance of the gastric mucosal barrier or preservation of renal function in patients with impaired renal function. As shown in this study, steroids have the property of inhibiting the induction of COX activity and do not affect the basal or constitutive activity in tissue. It remains to be seen if this activity of steroids on induced COX can be reproduced with other pharmacologic agents. Such agents would inhibit 
the induction of COX in sites of inflammation but not affect the COX in tissues such as the kidney or stomach and, speculatively, might have anti-inflammatory potential without renal or gastrointestinal toxicity.

\section{Acknowledgments}

The authors would like to thank J. Lefkowith for his excellent critiques and discussion, and Ms. Carol Patterson for typing the manuscript.

This work was supported by National Institutes of Health grants PO1 DK-38111 and RO1 HL-20787.

\section{References}

1. Vane, J. R., 1971. Inhibition of prostaglandin synthesis as a mechanism of action of aspirin-like drugs. Nature (Lond.). 231:232235.

2. Di Rosa, M., R. J. Flower, F. Hirata, L. Parente, and F. RussoMarie. 1984. Nomenclature announcement: anti-phospholipase proteins. Prostaglandins. 28:441-442.

3. Cirino, G., S. H. Peers, R. J. Flowers, J. L. Browning, and R. B. Pepinsky. 1989. Human recombinant lipocortin 1 has acute anti-inflammatory properties in the raw paw edema test. Proc. Natl. Acad. Sci. USA. 86:3428-3432.

4. Bronnegard, M., O. Anderson, D. Edwall, J. Lund, G. Norstedt, and J. Carlstedt-Duke. 1988. Human calpactin II (lipocortin I) messenger ribonucleic acid is not induced by glucocorticoids. Mol. Endocrinol. 2:732-739.

5. Davidson, F. F., E. A. Dennis, M. Powell, and J. R. Glenney. 1987. Inhibition of phospholipase $A_{2}$ by "lipocortin" and calpactins. $J$. Biol. Chem. 262:1698-1705.

6. Aarsman, A. J., G. Nunbeek, H. Van den Bosch, B. Rothhut, B. Prieur, C. Comera, L. Jordan, and F. Russo-Marie. 1987. Lipocortin inhibition of extracellular and intracellular phospholipases $A_{2}$ is substrate concentration dependent. FEBS (Fed. Eur. Biochem. Soc.) Lett. 219:176-180.

7. Moore, P. K., and J. R. S. Holt. 1980. Anti-inflammatory steroids reduce tissue $P G$ synthetase activity and enhance $P G$ breakdown. Nature (Lond.). 288:269-270.

8. Wood, J. N., P. R. Coote, and J. Rhodes. 1982. Hydrocortisone inhibits prostaglandin production but not arachidonic acid release from cultured macrophages. FEBS (Fed. Eur. Biochem. Soc.) Lett. 174:143-146.

9. Bailey, J., A. N. Makheja, J. Pash, and M. Verma. 1988. Corticosteroids suppress cyclooxygenase messenger RNA levels and prostanoid synthesis in cultured vascular cells. Biochem. Biophys. Res. Commun. 157:1159-1163.

10. Raz, A., A. Wyche, and P. Needleman. 1989. Temporal and pharmacological division of fibroblast cyclooxygenase expression into transcriptional and translational phases. Proc. Natl. Acad. Sci. USA. 86:1657-1661.

10a. Ji-Yi, F., J. L. Masferrer, K. Seibert, A. Raz, and P. Needleman. 1990. The induction and suppression of prostaglandin $\mathrm{H}_{2}$ synthase (cyclooxygenase) in human monocytes. J. Biol. Chem. In press.

11. Lefkowith, J. B. 1988. Essential fatty acid deficiency inhibits the in vivo generation of leukotriene $\mathrm{B}_{4}$ and suppresses levels of resident and elicited leukocytes in acute inflammation. J. Immunol. 140:228-233.

12. Brash, A. R. 1980. Metabolite measurement as an index of prostaglandin synthesis in vivo. In Prostaglandins, Prostacyclin and Tromboxane Measurement. J. M. Boeynaems and A. G. Herman, editors. Martinus Nijhoff, London. 137-138.

13. Nasjletti, A., A. Erman, L. M. Cagen, and P. G. Baer. 1984. Plasma concentrations, renal excretion, and tissue release of prostaglandins in the rat with dexamethasone-induced hypertension. Endocrinology. 114:1033-1040.

14. Fejes-Toth, N., G. Fejes-Toth, C. Fischer, and J. C. Frolich. 1984. Effect of dexamethasone on in vivo prostanoid production in the rabbit. J. Clin. Invest. 74:120-123.

15. Reines, H. D., P. V. Halushka, J. A. Cook, and C. B. Loadholt.
1985. Lack of effect of glucocorticoids upon plasma thromboxane in patients in a state of shock. Surg. Gynecol. \& Obstet. 160:320-322.

16. Hales, C. A., R. D. Brandstetter, C. F. Neely, M. B. Peterson, D. Kong, and W. D. Watkins. 1986. Methylprednisolone on circulating eicosanoids and vasomotor tone after endotoxin. J. Appl. Physiol. 86:185-191.

17. Freeland, H. S., R. P. Schleimer, B. A. Alger, and S. P. Peters. 1987. Leukotriene $B_{4}$ generation by human PMNs is not inhibited by glucocorticoids in vivo or in vitro. J. Allergy Clin. Immunol. 79:157.

18. Wallace, J. L. 1987. Glucocorticoid-induced gastric mucosal damage: inhibition of leukotriene, but not prostaglandin biosynthesis. Prostaglandins. 34:311-323.

19. Feben Reigold, D., K. Watters, S. Holberg, and P. Needleman. 1981. Differential biosynthesis of prostaglandins by hydronephrotic rabbit and cat kidneys. J. Pharmacol. Exp. Ther. 216:510-515.

20. Hayes, E. C., D. L. Lombardo, Y. Girard, A. L. Maycock, J. Rokach, A. S. Rosenthal, R. N. Young, R. W. Egan, and H. J. Zweekink. 1983. Measuring leukotrienes of slow reacting substances of anaphylaxis: development of a specific radioimmunoassay. J. Immunol. 131:429-433.

21. Bradford, M. 1976. A rapid and sensitive method for the quantification of microgram quantities of proteins utilizing the principle of protein-dye binding. Anal. Biochem. 72:248-254.

22. Needleman, P., A. Wyche, S. D. Bronson, S. Holmberg, and A. R. Morrison. 1979. Specific regulation of peptide-induced renal prostaglandin synthesis. J. Biol. Chem. 254:9772-9777.

23. Doherty, N. S., P. Poubelle, P. Borgeat, T. H. Beaver, G. L. Westrich, and N. L. Schrader. 1985. Intraperitoneal injection of zymosan in mice induces pain, inflammation and the synthesis of peptidoleukotrienes and prostaglandin $\mathrm{E}_{2}$. Prostaglandins. 30:769-789.

24. Lefkowith, J. B., B. A. Jakschik, P. Stahl, and P. Needleman. 1987. Metabolic and functional alterations in macrophages induced by essential fatty acid defficiency. J. Biol. Chem. 262:6668-6675.

25. Erman, A., and A. Nasjletti. 1984. Enhancement of renal medulla prostaglandin synthase activity by dexamethasone treatment in the rat. Biochem. Biophys. Res. Commun. 121:255-260.

26. Erman, A., J. A. Pitcock, T. Liston, P. Brown, P. G. Baer, and A. Nasjletti. 1987. Biphasic effect of dexamethasone on urinary prostaglandins in rats: relation to alterations in renal medulla triglycerides and prostaglandin metabolism. Endocrinology. 121:1853-1861.

27. Flower, R. J. 1988. Lipocortin and the mechanism of action of the glucocorticoids. Br. J. Pharmacol. 94:987-1015.

28. Bienkoski, M. J., M. A. Petro, and L. J. Robinson. 1989. Inhibition of thromboxane A synthesis in U937 cells by glucocorticoids. $J$. Biol. Chem. 264:6536-6544.

29. Raz, A., A. Wyche, N. Siegel, and P. Needleman. 1988. Regulation of fibroblast cyclooxygenase synthesis by interleukin-1. J. Biol. Chem. 263:3022-3028.

30. Habenicht, A. J. R., M. Goerig, J. Grulich, D. Rothe, R. Gronwald, U. Loth, G. Schletter, B. Kommerell, and R. Ross. 1985. Human platelet-derived growth factor stimulates prostaglandin synthesis by activation and by rapid de novo synthesis of cyclooxygenase. J. Clin. Invest. 75:1381-1387.

31. Hawkey, C. J. 1982. Evidence that prednisolone is inhibitory to the cyclooxygenase activity of human rectal mucosa. Prostaglandins. 23:397-409.

32. Schumer, W. 1981. Controversy in shock research. Pro: The role of steroids in septic shock. Circ. Schock. 8:667-671.

33. Bottoms, G. D., M. A. Johnson, C. H. Lamar, J. F. Fessler, and J. H. J. Turk. 1985. Endotoxin-induced eicosanoid production by equine vascular endothelial cells and neutrophils. Circ. Shock. 15:155-162.

34. Miller, T. A., and E. D. Jacobson. 1979. Progress report: gastrointestinal cytoprotection by prostaglandins. Gut. 20:75-87.

35. Ciabattoni, G., G. A. Cinotti, A. Pierucci, B. M. Simonetti, M. Manzi, F. Pugliese, P. Barsotti, G. Pecci, F. Taggi, and C. Patrono. 1984. Effects of sulindac and ibuprofen in patients with chronic glomerular disease: evidence for the dependence of renal function on prostacyclin. N. Engl. J. Med. 310:279-283. 